\title{
Variations in Park Facility Valuations across Neighborhoods
}

\author{
Tammy Leonard ${ }^{1 *}$, Lei Zhang², and Christy Hoehner ${ }^{3}$ \\ ${ }^{1}$ University of Dallas, Economics Department, 1845 Northgate Drive, Irving, TX \\ ${ }^{2}$ North Dakota State University, Agribusiness and Applied Economics Department, \\ 811 2nd Avenue N, Fargo, ND 58102 \\ ${ }^{3}$ Washington University School of Medicine, 660 S. Euclid Avenue, St. Louis, MO \\ *Corresponding Author: phone-972-883-2970; email-TLeonard@udallas.edu
}

Abstract

The obesity epidemic has renewed policy interest in provision of physical activity-enhancing park facilities. Public health researchers have noted variability in physical activity levels associated with different types of facilities. We assess the hedonic valuation of different types of park facilities. For homes located $1 / 4 \mathrm{mile}$ from the nearest park, the hedonic value of a 1/10 mile improvement in proximity ranges from an $1.3 \%$ increase in home price in African American neighborhoods to a $0.3 \%$ price reduction in "average" neighborhoods. Similar variation occurs across the home price distribution, park facilities, and neighborhood characteristics. Park funding implications are discussed.

Keywords: spatial econometrics, hedonic, physical activity, parks

JEL Codes: I1, R3, R5, H2, H4

Acknowledgements: We thank Wenyuan Yin and Christine Marx for outstanding GIS support. 


\section{Variations in Park Facility Valuations across Neighborhoods}

\section{Introduction}

Considerable public and private funds are used to enhance the built environment in ways that encourage physical activity through more/improved recreational facilities. The public health literature has provided documentation of numerous positive relationships between facilities and physical activity levels (Heath et al. 2006; Humpel et al. 2002; Kahn et al. 2002; Saelens et al. 2003) and the health benefits of increased physical activity are also well known (Pratt et al. 2000; DHHS 2008; Physical Activity Guidelines Advisory Committee Report, 2008 2008). However, little work has been done to uncover the market or hedonic (marginal) price of these particular neighborhood enhancements. A recent study documenting changes in park use associated with upgrades to park facilities found a negative relationship (i.e. decreased park use after upgrades) (Deborah A. Cohen et al. 2009). Understanding the market valuations of physical activity-enhancing improvements to the built environment is important for informing public policy about how, on average, existing park facilities are valued.

A significant literature has examined the hedonic price of proximity to open spaces or parks in general (Anderson and West 2006; Asabere and Huffman 2009; Brown and Pollakowski 1977; Crompton 2001; Espey and Owusu-Edusei 2001; Irwin 2002). However, parks differ substantially in the facilities offered, which suggests there might be significant variation in the hedonic price of proximity. The goal of this paper is to estimate the hedonic price of the distance to different types of park facilities. We do this while allowing the hedonic price to vary across neighborhood characteristics and across the conditional 
house price distribution. In particular, we will focus on those facilities that are most likely to encourage child physical activity. This addresses the key motivation for this study: are built environment improvements that provide increased opportunities for child physical activity valued in the housing market? If so, this valuation provides important information regarding society's marginal willingness to pay for these facilities. The estimates we obtain may be interpreted as the "average treatment on the treated" effects because they measure the average willingness to pay for proximity to park facilities in neighborhoods where the facilities already exist. While this does not inform price changes that may be expected for new facilities, it does have important implications for the funding of existing facility upkeep through user fees and property taxes. These implications will be discussed.

Next we will further motivate the research question and describe the empirical approach and data. The remainder of the paper will report on the results and examine resulting policy implications.

\section{Background}

Parks and recreation facilities provide an important outlet that may encourage youth physical activity. For adolescents age 10-17, living in a neighborhood with a park or recreational facility has been associated with a decreased likelihood of being overweight or obese (Bethell et al. 2010). Parks vary in the facilities offered and these have been found to significantly influence the degree to which proximity to the park is related to physical activity. Playgrounds, trails and paths, swimming areas, and ball courts have been related to increased physical activity while picnic shelters and grills have had the opposite effect (D. A. Cohen et al. 2006; Shores and West ; A. T. Kaczynski and Havitz 2009). For young children (age 5-10) swimming pools, small public parks, playgrounds, play fields/courts, 
and large public parks were the most commonly used recreational facilities while adolescents (age 11-18) have reported indoor recreation facilities and walk/run tracks as being highly utilized (A. Kaczynski et al. 2008). Park use among kids also varies by sociodemographic characteristics. For example, in California it was found that inner-city Hispanic children were more likely to prefer large parks with athletic fields than their nonHispanic counterparts.(Loukaitou-Sideris and Sideris 2009)

Since utilization of park facilities varies by age group, we would likewise expect that the hedonic price of parks would vary by neighborhood type. Those neighborhoods that have a higher proportion of likely users of the nearby park, likely value the park more. For example, parks with playgrounds might command a higher hedonic price in neighborhoods with young children.

\section{The Economics of Built Environment Improvements}

Numerous initiatives have been put into place to encourage communities to make physical activity enhancing improvements to the built environment. For example, the Centers for Disease Control and Prevention's Active Community Environments Initiative promotes walking, bicycling, and improved access to recreational facilities(CDC 2010). Likewise, Safe Routes to School (SR2S) is a federally funded program aimed at encouraging children to safely walk and bicycle to school. Beginning in 2005, the federal government apportioned $\$ 612$ million over 5 years (SR2S 2010) to the SR2S effort and other similar projects are funded at lower levels of government. Most built environment improvements may be categorized as either improvements to the recreational facilities (destinations) or as improvements to the surrounding transportation infrastructure. 75 percent of American 
households live within 2 miles of a park (ICMA and NACO 2006), thus enhancing existing park facilities is a key aim of the U.S. National Physical Activity Plan (National Physical Activity Plan 2010).

While significant investments are being made to improve the built environment as a response to public health concerns regarding the relationship between environment and physical activity, successful projects engage a broad array of sectors and individuals (Simon and Fielding 2009). This diverse group includes community coalitions, planners, transportation officials, parks and recreation departments, schools, developers, private businesses, and community residents. Rallying such a diverse group around a common initiative is more easily accomplished when the benefits accrue to all involved in a salient way. Assessing the full economic return of the public expenditures provides such a measure. The majority of parks in the United States are community parks funded through tax dollars or local bonds (A. J. Mowen et al. 2006); but there is growing pressure for privatization of park funding through user fees, sponsorships or donations (A. J. Mowen et al. 2006). Understanding the degree to which parks influence property values is an important part of the discussion regarding how park improvements and upkeep should be financed.

A significant literature exists which documents a positive empirical relationship between proximity to parks or open space and residential home values (Crompton 2001; Irwin 2002; Irwin and Bockstael 2001). However, much less work has been done to understand the economic value of features of parks/open space that are most highly utilized by youth—and hence are central to the policy initiative aimed at reducing childhood obesity. A few studies broadly differentiated between active use (parks offering 
playgrounds, ball fields, etc.) or passive use parks (parks offering more contemplative experiences). Passive use parks were found to be more valuable in terms of incremental increases in neighboring property values than active use parks that sometimes were found to decrease the value of neighboring properties (More et al. 1982, 1988; Weicher and Zerbst). More recent studies have analyzed specific park facilities providing empirical evidence that proximity to greenbelts with trails and small parks with playground facilities are more beneficial to neighboring property values than parks without these facilities (Asabere and Huffman 2009; Espey and Owusu-Edusei 2001).

However, one of the key problems plaguing much of the existing literature is the lack of adequate controls for neighborhood characteristics. Individuals living closer to a park are more likely to use it (Grow et al. 2008; A. Mowen et al. 2007). Thus, the degree to which recreational facilities are capitalized into house values may depend upon many factors related to the composition of the nearby neighborhood residents: e.g., race/ethnicity, income, or the presence of households with children. For example, it was found that families with children value neighborhood parks more than other households. However, "special parks"--parks such as state parks, arboretums or natural areas-are more valuable to middle-aged households (Anderson and West 2006). We will augment this literature by analyzing how proximity to different park facilities is valued in different types of neighborhoods. The facilities that we focus on are those noted to be associated with increased child physical activity: ball fields and playgrounds.

Even after controlling for the moderating effect of neighborhood characteristics on the hedonic price of park proximity, the conditional distribution of house prices is unlikely to be symmetric. Preferences for parks vary across different sub-populations (Hutchison 
1987; Tinsley et al. 2002). The variation in preferences and park distribution may in part be related to the neighborhood characteristics that we measure directly, but it might also be associated with other factors which vary with housing prices. Quantile regression (QR) models estimate the hedonic price of park proximity for different quantiles of the distribution of house prices. If the conditional distribution of house prices is asymmetric, then the hedonic price of park proximity estimated via ordinary least squares will be biased and quantile regression estimates will provide a more descriptive picture of how park proximity is valued in the housing market (Koenker and Hallock 2001). Additionally, the QR estimated results are directly related to policy that may target changes in neighborhoods within a particular segment of the house price distribution. Other authors have found variation in hedonic price estimates across quantiles of the housing market for housing characteristics (Zietz et al. 2008; Liao and Wang 2012), proximity to agriculture and waste facilities (Kuethe and Keeney 2012), and location within a historic preservation district (Zahirovic-Herbert and Chatterjee 2012).

\section{Econometric Model}

We use a hedonic price model (C. W. Kim et al. 2003; Rosen 1974) to estimate the marginal price of park proximity. A home's market price, $P_{h}$, is related through a hedonic price function to the home's attributes, $X_{h}$, and it's locational characteristics $N_{h}$, which include proximity to neighborhood facilities:

$$
P_{h}=f\left(X_{h}, N_{h}\right)
$$

We are primarily interested in the hedonic value of proximity to park facilities controlling for housing characteristics and average neighborhood home values. Inclusion of 
neighborhood home values in the model suggests a classic spatial lag model (Anselin 1988). The hedonic price function we will estimate is given by

$$
\ln (P)=\rho W \ln (P)+\beta_{1} X+\beta_{2} D+\sum_{a \in A}\left\{d_{a}\left[\lambda_{a}+\gamma_{a} z+\delta_{a} s_{a}\right]+\theta_{a} d_{a}{ }^{2}\right\}+\epsilon
$$

where $\ln P$ is the natural $\log$ of home sale price, $X$ is a matrix of house characteristics and $D$ is a matrix of dummy variables to control for the month which the home sale took place and school district in which the house is located. The spatial weights matrix, $W$, identifies the neighboring houses. All houses for which a sale price is available that are within 2000 feet of the property of interest are considered neighbors; $W$ weights neighbors by inverse distance from the property of interest, and then the matrix is row-standardized. The variables of greatest interest in the model are to the right of the summation sign. The distance to park facilities is given by $d_{a}$, where the subscript $a$ identifies different facility types: any park, playgrounds and ball fields. ${ }^{1}$ In a method similar to that employed by Anderson and West (2006), we include the distance variable independently, and then interact it with characteristics of the neighborhood surrounding the house for which the hedonic price is being estimated and park size. Neighborhood characteristics are contained in the matrix, $z$ and the size of the park containing facility $a$ is given by $s_{a}$. We also include distance to the nearest park squared to account for non-linear distance effects. All variables included in $s$ and $z$ have been standardized so that they have mean of 0 and standard deviation of 1 . This approach facilitates a nice interpretation of the marginal effects of park proximity. The semi-elasticity of sale price with respect to distance to park facility $a$ is given by

\footnotetext{
${ }^{1}$ For cases where parks have more than one facility, we include the distance to the park for each facility type.
} 


$$
\frac{\partial E[\ln (P)]}{\partial d_{a}}=(I-\rho W)^{-1}\left[\lambda_{a}+\gamma_{a} z+\delta_{a} s_{a}+2 \theta_{a} d_{a}\right]
$$

$W$ is a row-standardized weight-matrix, therefore the first term reduces to $(1-\rho)^{-1}$ (C. W. Kim et al. 2003; LeSage and Pace 2009). If the estimated $\rho$ is positive and less than 1, then $(1-\rho)^{-1}$ is simply a constant weighting factor and for simplicity we will disregard it in the discussion below and we consider only the direct effect of proximity. ${ }^{2}$ Since $\mathrm{z}$ and $s$ are standardized, $\lambda_{\mathrm{a}}$ gives the average price semi-elasticity of proximity for facility $a$ for houses in neighborhoods with average characteristics. Similarly, $\gamma_{a}$ is a vector of the incremental change in the price semi-elasticity of proximity when neighborhood characteristics increase by one standard deviation; and $\delta_{a}$ is a vector of the incremental change in the price semi-elasticity of proximity when the size of the park in which the facility is located changes by 1 standard deviation. A negative price semi-elasticity indicates that price increases when distance to the park facility decreases.

As mentioned previously, we will use quantile regression (QR) to estimate a unique hedonic price of park facilities for each decile of the conditional distribution of house sale prices. Quantile regression uses the entire sample of house prices avoiding truncation problems that may be encountered when estimating independent regression models for each strata of the dependent variable (Heckman 1979). Instead of minimizing the sum of squared residuals as in the case of ordinary least squares (OLS) regression, QR minimizes the weighted sum of absolute residuals. For the model specified in (2), QR will estimate the coefficients that solve

2 The direct effect of proximity to parks is given by the terms inside the square brackets in (3). Indirect effects work through the spatial multiplier, $\rho$, and exist because house prices are spatially correlated (LeSage and Pace 2009). 
Weights, $\omega_{n}$, are unique for each observation, $n$, and determined by the quantile being estimated.

$\omega_{n}=2 \mathrm{q}$

if the residual for the nth observation is strictly positive or

$\omega_{n}=2-2 q$

if the residual for the nth observation is negative or zero.

For the median quantile, $\mathrm{q}=0.5$, weights are constructed so that the optimal solution occurs when 50 percent of the residuals are negative. If the conditional distribution of house price is symmetric, the $\mathrm{q}=0.5$ case should correspond to OLS regression estimates. However, if the conditional distribution of house price is not symmetric, the results will vary. The spatial lag model in (2) presents an endogeneity problem for standard quantile regression. We use the double-stage quantile regression (DSQR) estimator (T.-H. Kim and Muller 2004) to handle the endogeneity concern. The standard errors are obtained through 500 bootstrap replications (Greene 2008).

\section{Data}

Sales data for single family residences comes from real-estate transactions in Dallas County, Texas. Housing market sale price data for 2008 were obtained from the University of Texas at Dallas Real Estate Research Database and were used to construct the model's 
dependent variable. ${ }^{3}$ The database also contains housing characteristics and date of sale that are included in the $X$ and $D$ terms of the model, respectively. Neighborhood characteristic data was obtained from the American Community Survey 2006-2010 5-year estimates (US Census). For each block group we calculate the percent of the population that is less than 5 years of age (agelt5) and the percent of the population that is 6-17 years of age (school_aged). We also calculate the race/ethnicity, and income composition of each block group.

Park location data was obtained from the North Central Texas Council of Governments who used aerial photography to identify parks. The data was subsequently cleaned to remove any green spaces that were not recreational parks (i.e. cemeteries, large "medians", etc.) and the data was augmented with an extensive web search of local parks and recreation departments to identify the facilities associated with each park (Marx 2011). For this study we will focus our attention on two types of facilities: ball fields and playgrounds. For each house that sold in 2008, we calculated the distance along the street network between the house and the nearest park of each type using ArcMap Network Analyst. Network analyst requires the parks to be represented as a single point for analysis. For parks less than 0.03 square miles, we used the park centroid. For larger parks, we used ET GeoWizards add-on for ArcMap to construct points along the boundaries of parks. In total we identified 1919 parks in Dallas County. 873 contain ball fields (45.5

\footnotetext{
3 There is some concern that the financial recession of 2007-2008 may have affected home sales in high/low income neighborhoods differently. However, the housing market in Dallas County was less affected than housing markets in other regions of the country. Additionally, comparative sales volume in low-, medium- and high- income neighborhoods in Dallas Country were approximately the same in 2008 as before the financial recession (i.e. 2005).
} 
percent), 1072 have playgrounds (55.9 percent), and 682 (35.5 percent) have both ball fields and playgrounds.

The summary characteristics for the housing and neighborhood data are displayed in Table 1 . The average house is 35 years old and has just over 2000 square feet of living area. Most houses (72 percent) have a single level, have central air conditioning (93 percent) and at least one fireplace (71 percent). The condition of the houses is rated according to 7 categories where condition 1 indicates houses in the best condition (19 percent) and Condition 7 indicates houses in the worst condition ( 2 percent). The average distance between properties that sold in 2008 and a park is 0.67 miles. This distance increases when we look at only parks with a playground (0.93 miles), or ball field (1.07 miles).

Since we will be estimating the modifying effect of neighborhood characteristics on park proximity throughout the house price distribution, we are also interested in understanding how the distribution of parks varies along these dimensions. Table 2 displays the average distance to each type of park for neighborhoods whose characteristics are 2 standard deviations above the mean. The average proximity to parks varies a little for these sub-samples, but largely they mirror the sample averages suggesting that even among neighborhoods whose characteristics differ significantly from the mean, parks are fairly evenly distributed. Table 3 reports the average proximity of houses to parks within each decile of the price distribution and again we find that the distribution of parks is fairly similar across the house price distribution. These results also help to alleviate the concern that park citing may be endogenously determined. In most cases, the public parks in our sample have been established for a considerable length of time. The parks have been in 
existence as neighborhoods have changed. Additionally, the 2 types of facilities we examine-playgrounds and ball fields—have also not experienced a great deal of change suggesting they have not been endogenously determined by preferences of current neighborhood residents. This along with the observed fairly similar access to parks across the different sub-samples examined in Tables 2 and 3 is suggestive that park distribution is exogenous to the current distribution of housing and neighborhood characteristics.

\section{Estimation and Results}

We begin by estimating (2) while restricting the park facility to be of only 1 typeany park; estimation results are presented in Table 4. Next, we distinguish between the different types of park facilities and estimate the hedonic price of proximity to ball fields and playgrounds, while controlling for proximity to the nearest park; estimation results are displayed in Table 5. In both cases we first estimate a baseline mean regression model and then a QR model. For both models, we instrument for the average sale price in the neighborhood by using the spatial lag of the housing characteristics as instruments according to the DSQR approach (T.-H. Kim and Muller 2004). In all of the hedonic models, coefficients for housing characteristics are as expected. Older homes generally sell at a discount, while larger homes, homes with central heat, homes with fireplaces, and homes with a pool command a premium in the market.

The estimation results allow for comparison of the hedonic price of parks across different types of park facilities, types of neighborhoods and deciles of the house price distribution. To facilitate this, we calculate the semi-elasticity of park proximity given by $(3)^{4}$. A negative semi-elasticity indicates that the facility is related to an increase in nearby

\footnotetext{
${ }^{4}$ The calculated semi-elasticities include only the direct effect of park proximity.
} 
house prices; we will refer to proximity to these features as being valued as an "amenity". In contrast, a positive semi-elasticity indicates that proximity to the facility is associated with a decrease in nearby house prices; we will refer to proximity to these features as being valued as a "dis-amenity". Because we allow the hedonic price of park proximity to vary non-linearly, all semi-elasticities will vary with distance. In what follows, we first compare how the semi-elasticities for each park facility change with distance. Then, we compare semi-elasticities in different types of neighborhoods while holding the distance constant.

\section{Semi-elasticity of Park Proximity in Neighborhoods with Average Characteristics}

Figure 1 illustrates the semi-elasticity of park proximity for neighborhoods with average race/ethnicity, income, and age characteristics and the variation in elasticity with distance from the park. Recall, the neighborhood characteristic variables were standardized before including them in the model; thus, the elasticities represented in Figure 1 are those for which all of the neighborhood characteristic variables are equal to zero. In each panel, elasticities for the mean regression and each decile are plotted at varying distances. Cases in which the proximity to the nearest park was not statistically significant are indicated by a dashed line in the plots.

Figure 1(a) illustrates semi-elasticity of park proximity for parks of any type.

Positive elasticities for houses approximately 0.75 miles or greater from the park represent a market discount (or penalty) for not being near a park in the upper deciles of the house price distribution. In the mean regression, houses greater than 0.45 miles from the nearest park have a positive semi-elasticity; over $73 \%$ of the sample is greater than 0.4 miles from the nearest park. The elasticity of park proximity is statistically significant in all but the $2^{\text {nd }}$ 
decile of the house price distribution; park proximity is valued more in the higher deciles of the home price distribution.

Proximity to ball fields (Figure 1(b)) is a dis-amenity in neighborhoods with average characteristics. The disamenity affect varies little with distance in the lower quantiles. In contrast, coefficient estimates for proximity to playgrounds (Figure 1(c)) are not statistically different from zero in the mean regression and in most deciles.

Considering park size, the estimates in Tables 4 and 5 indicate that ballfields located in large parks are more of a disamenity in the lower deciles. However, playgrounds and proximity to any park are valued more as park size increases.

\section{Semi-elasticity of Park Proximity for Neighborhoods with Racial/Ethnic Minority}

\section{Concentrations}

Figure 2 presents the estimated elasticities of park proximity for houses $1 / 4$ mile from the park in neighborhoods with 2 standard deviations higher percentage of African American, Asian, or Hispanic residents. In all cases, the largest elasticities (in absolute value) are for areas with higher concentrations of African American population followed by higher concentrations of Hispanics. The smallest effect sizes are for neighborhoods with 2 standard deviations more Asian residents. The small effect size for Asian neighborhoods, however, may be driven by the sample, which includes far fewer neighborhoods with high concentrations of Asian residents compared to the prevalence of neighborhoods with high concentrations of African Americans or Hispanics. The mean neighborhood proportion of Asian residents in the sample is 5\% compared to $22 \%$ (mean proportion black) and $27 \%$ (mean proportion Hispanic). 
In general, proximity to parks of any type (Figure 2(a)) is an amenity in neighborhoods with large ethnic minority populations and the value of proximity increases with increasing house price. The effects of proximity to parks are particularly strong in ethnic-minority neighborhoods: the highest elasticities (in absolute value) for any of the park-decile-neighborhood characteristics are estimated for proximity to parks of any type in the upper deciles for neighborhoods with large African American and Hispanic populations. Proximity to ball fields (Figure 2 (b)), while a dis-amenity in "average" neighborhoods, is an amenity in neighborhoods with ethnic minority concentrations in all but the very lowest deciles of the home price distribution. Playgrounds (Figure 2(c)) are always an amenity for neighborhoods with high African American and Hispanic concentrations.

\section{$\underline{\text { Semi-elasticity of Park Proximity for Neighborhoods with Varying Income Distributions }}$}

Figure $2(d)$ presents the semi-elasticity of park proximity for houses $1 / 4$ mile from the park in neighborhoods with 2 standard deviation higher percentage of households whose income is below $200 \%$ of the federal income poverty line. $51 \%$ of children in Texas live in households below 200\% of the poverty level (Children Below 200\% Poverty 2011). Proximity to playgrounds only has a statistically significant semi-elasticity in the third lowest decile where it is an amenity and in the highest 2 deciles where it is a dis-amenity. In almost all deciles of the house price distribution, however, ball fields are an amenity in contrast to their characterization as dis-amenities in "average" neighborhoods. Proximity to any park is always an amenity, with larger effect sizes as house prices increase. 


\section{Semi-elasticity of Park Proximity for Neighborhoods with Kids}

Results in Tables 4 and 5 also indicate that in neighborhoods with more children less than 5 years old, ball fields are considered more of a dis-amenity in the upper deciles of the conditional home price distribution, but in neighborhoods with more school-aged children ball fields are considered more of an amenity in the lower deciles of the price distribution. In contrast, proximity to playgrounds is considered more of an amenity in upper deciles in neighborhoods with more young children; while proximity to playgrounds does not have a statistically significant coefficient estimate in any decile in neighborhoods with more school-aged children.

\section{Discussion and Conclusion}

Our results highlight the large variation in the hedonic price of park facilities according to both the distribution of house prices and neighborhood characteristics. In the mean regression, considering proximity to parks of any type in neighborhoods with average characteristics, we found that being near to a park is associated with higher home prices and being further than 0.45 mile from a park is associated with a decrease in home prices. By far the strongest effects for park proximity were found when considering proximity to parks of any type for neighborhoods with large African American and Hispanic populations and in the upper deciles of house prices. For example, the price semi-elasticity at $1 / 4$ mile from the nearest park in a neighborhood with 2 standard deviations higher African American population in the $6^{\text {th }}$ decile of the house price distribution is -0.159 . This translates into a $1.6 \%$ increase in home price for every $1 / 10$ mile decrease in distance from the park; in contrast proximity to any park in average neighborhoods in the bottom decile is associated with a $0.3 \%$ (semi-elasticity $=0.03$ ) decrease in home price for every $1 / 10$ mile 
decrease in distance from the park. The hedonic price of proximity to ball fields exhibits some of the most significant heterogeneity across neighborhood types. For example, for homes in the $4^{\text {th }}$ decile located $1 / 4$ mile from the nearest ball field, being $1 / 10$ mile closer is associated with a $0.1 \%$ decrease (semi-elasticity $=0.01$ ) in home prices in neighborhoods with average characteristics, but it is associated with a $1.02 \%$ increase (semi-elasticity=0.102) in home price in neighborhoods with 2 standard deviations more African American residents. Considering a median home price of $\$ 124,000$, a $1 / 10$ mile improvement in park proximity translates into a decrease of $\$ 124$ or an increase of $\$ 1265$, respectively. It is possible that the results are influenced by the fact that some households may be forced to reside in higher density neighborhoods and the lack of open space results in a stronger preference for park accessibility. However, we see only modest hedonic prices for park proximity among low-income neighborhoods.

Our results are similar to other results in the literature regarding the hedonic price of park proximity, however, they indicate more heterogeneity than other studies have reported. For instance, it has been reported that active use parks in Mineapolis are associated with price declines.(Lin et al. 2013) We find that ball field proximity is almost always considered a dis-amenity, but there are a few exceptions. Ball field proximity is related to increased property values (or only small decreases in property values) in African American and Hispanic neighborhoods, neighborhood with a larger concentration of lowto-middle income households, and in neighborhoods with a high proportion of minority, school-aged kids. Considering the demographic distribution of households in Dallas County, these characteristics are most predominant in the southern half of the county. The variations in the hedonic price of ball fields may be related to congestion associated with 
ball field use or variations in the ways in which ball fields are sited and/or used in different neighborhoods. In a survey of California parks, ball fields and gymnasiums were the busiest facilities accounting for $24.6 \%$ of all park users (Deborah A. Cohen et al. 2010). Considering park size, ballfields are considered more of a dis-amenity when they are associated with larger parks in the lower deciles of the house price distribution.

The hedonic price of park facilities provides an average measure of existing residents' average marginal willingness to pay for the existing park facilities. Negative semi-elasticities indicate the extent to which neighborhood residents would (and in fact are) willing to pay a premium for living near to park facilities. This suggests some bounds on the extent to which user fees might be used to fund parks (or park improvements). For the case of ball fields where proximity is often associated with a decrease in home values, user fees might be well justified and be used to provide services which might off-set some of the local congestion dis-amenities often associated with ball fields (e.g. better policing, street or parking improvements). The hedonic price of park proximity may be used as an upper bound on neighborhood residents' marginal willingness to pay for park usage.

Our results should be viewed in light of the study's limitations. First, the sample is taken from a single county and the representativeness of this county is unknown. Housing density, utilization rates for public transportation, weather conditions, neighborhood diversity, and ethnic composition are all factors which may limit the external validity of these results to other regions which differ along these parameters. Additionally, the neighborhood characteristics data were based on census block group boundaries due to data limitations and data regarding the quality and safety of park facilities was not available and hence omitted from the analysis. Some housing submarkets may be primarily 
composed of households with similar characteristics. Because hedonic price estimates are a reflection of preferences of only the market participants, not all estimates are representative of the preferences of the entire population. Finally, data was not available on longitudinal changes in the characteristics or quality of parks. Additionally analysis of this type of data would provide important information about the causal effect of new parks or amentities on property values.

Our results highlight the important need to consider the wide variation in parks and neighborhood composition when assessing the economic impact of park facilities. Mean regression results mask the large variation in the hedonic price of park proximity within the house price distribution. Additionally, the hedonic price of park proximity varies considerably across neighborhood types.

In conclusion, the results presented here provide vital information regarding the economic efficiency of provision of public park facilities. They highlight the variation in hedonic price of proximity to neighborhood parks and can be used to inform important policy questions regarding how to best allocate funding for public facilities and the degree to which these investments are valued in diverse neighborhoods. While previous work has grouped neighborhood parks into a homogenous land use category, we provide evidence that their valuation in local housing markets is heterogeneous.

Funding: This study was funded by the Robert Wood Johnson Foundation Active Living Research (RWJ 68501) 


\section{References}

Anderson, S. T., \& West, S. E. (2006). Open space, residential property values, and spatial context. Regional Science and Urban Economics, 36(6), 773-789.

Anselin, L. (1988). Spatial Econometric: Methods and Models (Vol. Book, Whole). Dordrecht: Kluwer.

Asabere, P. K., \& Huffman, F. E. (2009). The Relative Impacts of Trails and Greenbelts on Home Price. Journal of Real Estate Finance and Economics, 38(4), 408.

Bethell, C., Simpson, L., Stumbo, S., Carle, A. C., \& Gombojav, N. (2010). National, State, And Local Disparities In Childhood Obesity. Health Affairs, 29(3), 347-356.

Brown, G. M., \& Pollakowski, H. O. (1977). Economic valuation of shoreline. The review of economics and statistics, 59(3), 272.

CDC (2010). ACES--Active Community Environments. (Vol. 2010): Center for Disease Control and Prevention.

Children Below 200\% Poverty (2011). http://datacenter.kidscount.org/data/acrossstates/Rankings.aspx?ind=47. Accessed November 12, 20122012.

Cohen, D. A., Ashwood, J. S., Overton, A., Staten, L. K., \& McKenzie, T. (2006). Public parks and physical activity among adolescent girls. Pediatrics, 118(5), e1381.

Cohen, D. A., Golinelli, D., Williamson, S., Sehgal, A., Marsh, T., \& McKenzie, T. L. (2009). Effects of Park Improvements on Park Use and Physical Activity: Policy and Programming Implications. American Journal of Preventive Medicine, 37(6), 475-480, doi:http://dx.doi.org/10.1016/j.amepre.2009.07.017.

Cohen, D. A., Marsh, T., Williamson, S., Derose, K. P., Martinez, H., Setodji, C., et al. (2010). Parks and physical activity: Why are some parks used more than others? Preventive Medicine, 50, Supplement(0), S9-S12, doi:http://dx.doi.org/10.1016/i.ypmed.2009.08.020.

Crompton, J. L. (2001). The impact of parks on property values: a review of the empirical evidence. Journal of Leisure Research, 33(1), 1.

DHHS (2008). Physical Activity Guidelines Advisory Committee Report. In P. A. G. A. Committee (Ed.). Washington, D.C.: Department of Health and Human Services.

Espey, M., \& Owusu-Edusei, K. (2001). Neighborhood Parks and Residential Property Values in Greenville, South Carolina. Journal of Agricultural and Applied Economics, 33(3), 487-492.

Grow, H. M., Saelens, B. E., Kerr, J., Durant, N. H., Norman, G. J., \& Sallis, J. F. (2008). Where are youth active? Roles of proximity, active transport, and built environment. Medicine and science in sports and exercise, 40(12), 2071.

Heath, G. W., Brownson, R. C., Kruger, J., Miles, R., Powell, K. E., Ramsey, L. T., et al. (2006). The effectiveness of urban design and land use and transport policies and practices to increase physical activity: a systematic review. J Phys Activ Health, 3(IS), S55-76.

Heckman, J. J. (1979). Sample Selection Bias as a Specification Error. Econometrica, 47(1), 153-161.

Humpel, N., Owen, N., \& Leslie, E. (2002). Environmental factors associated with adults,Äô participation in physical activity A review. American Journal of Preventive Medicine, $22(3), 188$. 
Hutchison, R. (1987). Ethnicity and urban recreation: Whites, Blacks and Hispanics in Chicago's public parks. Journal of Leisure Research, 19, 17.

ICMA, \& NACO (2006). Active Living Approaches by Local Government.

Irwin, E. G. (2002). The effects of open space on residential property values. Land Economics, 78(4), 465.

Irwin, E. G., \& Bockstael, N. E. (2001). The problem of identifying land use spillovers: Measuring the effects of open space on residential property values. American Journal of Agricultural Economics, 83(3), 698.

Kaczynski, A., Potwarka, L. R., \& Saelens, B. E. (2008). Association of park size, distance, and features with physical activity in neighborhood parks. American Journal of Public Health, 98(8), 1451-1456.

Kaczynski, A. T., \& Havitz, M. E. (2009). Examining the Relationship between Proximal Park Features and Residents' Physical Activity in Neighborhood Parks. Journal of Park \& Recreation Administration, 27(3), 18.

Kahn, E. B., Ramsey, L., \& Brownson, R. C. (2002). The effectiveness of interventions to increase physical activity. American Journal of Preventive Medicine, 22(4S), 73.

Kim, C. W., Phipps, T. T., \& Anselin, L. (2003). Measuring the Benefits of Air Quality Improvement: A Spatial Hedonic Approach. Journal of Environmental Economics and Management, 45, 15.

Kim, T.-H., \& Muller, C. (2004). Two-stage quantile regression when the first stage is based on quantile regression. [10.1111/j.1368-423X.2004.00128.x]. Econometrics Journal, $7(1), 218-231$.

Koenker, R., \& Hallock, K. F. (2001). Quantile Regression. The Journal of Economic Perspectives, 15(4), 143-156.

Kuethe, T. H., \& Keeney, R. (2012). Environmental Externalities and Residential Property Values: Externalized Costs along the House Price Distribution. Land Economics, 88(2), 241-250.

LeSage, J., \& Pace, R. K. (2009). Introduction to Spatial Econometrics: CRC Press/Taylor \& Francis Group.

Liao, W.-C., \& Wang, X. (2012). Hedonic house prices and spatial quantile regression. Journal of Housing Economics, 21(1), 16-27, doi:10.1016/j.jhe.2011.11.001.

Lin, I.-H., Wu, C., \& De Sousa, C. (2013). Examining the economic impact of park facilities on neighboring residential property values. Applied Geography, 45, 322-331.

Loukaitou-Sideris, A., \& Sideris, A. (2009). What brings children to the park? Analysis and measurement of the variables affecting children's use of parks. Journal of the American Planning Association, 76(1), 89-107.

Marx, C. (2011). unknown--a work in progress.

More, T. A., Stevens, T. H., \& Allen, P. G. (1982). The economics of urban parks: A benefit/cost analysis. Parks Recreation, 17(8), 31.

More, T. A., Stevens, T. H., \& Allen, P. G. (1988). Valuation of urban parks. Landscape and Urban Planning, 15(1-2), 139.

Mowen, A., Orsega-Smith, E., Payne, L., Ainsworth, B., \& Godbey, G. (2007). The role of park proximity and social support in shaping park visitation, physical activity, and perceived health among older adults. Journal of physical activity \& health, 4(2), 167179. 
Mowen, A. J., Kyle, G. T., Borrie, W. T., \& Graefe, A. R. (2006). Public Response to Park and Recreation Funding and Costsaving Strategies: The Role of Organizational Trust and Commitment. [Article]. Journal of Park \& Recreation Administration, 24(3), 72-95.

National Physical Activity Plan (2010). http://www.physicalactivityplan.org/parks.php.

. Physical Activity Guidelines Advisory Committee Report, 2008 (2008). In P. A. G. A. Committee (Ed.). Washington, D.C.: U.S. Department of Health and Human Services.

Pratt, M., Macera, M. A., \& Wang, G. (2000). Higher direct medical costs associated with physical inactivity. Physician Sportsmed, 28, 7.

Rosen, S. (1974). Hedonic prices and implicit markets: product differentiation in pure competition. The journal of political economy, 82(1), 34.

Saelens, B. E., Sallis, J. F., \& Frank, L. D. (2003). Environmental correlates of walking and cycling: findings from the transportation, urban design, and planning literatures. Annals of behavioral medicine, 25(2).

Shores, K. A., \& West, S. T. The Relative Importance of Individual and Environmental Attributes for Active Park Use. In Proceedings of the 2006 Cooper Institute Conference on Parks, Recreation and Public Health, (Vol. Dallas, TX)

Simon, P. A., \& Fielding, J. e. (2009). Establishing Best Practices for Changing the Built Environment to Promote Physical Activity. American Journal of Preventive Medicine, $37(6)$, S448.

SR2S (2010). Safe Routes to School. (Vol. 2010): National Center for Safe Routes to School.

Tinsley, H. E. A., Tinsley, D. J., \& Croskeys, C. E. (2002). Park Usage, Social Milieu, and Psychosocial Benefits of Park Use Reported by Older Urban Park Users from Four Ethnic Groups. Leisure sciences, 24(2), 199-218, doi:10.1080/01490400252900158.

Weicher, J. C., \& Zerbst, R. H. February 1973,„ÄúThe Externalities of Neighborhood Parks: An Empirical Investigation,,Äù. Land Economics, 49(1), 99.

Youth Risk Behavior Surveillance Survey. http://apps.nccd.cdc.gov/youthonline/App/QuestionsOrLocations.aspx?CategoryId =5. Accessed May 28, 2012.

Zahirovic-Herbert, V., \& Chatterjee, S. (2012). Historic Preservation and Residential Property Values: Evidence from Quantile Regression. Urban Studies, 49(2), 369-382.

Zietz, J., Zietz, E., \& Sirmans, G. (2008). Determinants of House Prices: A Quantile Regression Approach. The Journal of Real Estate Finance and Economics, 37(4), 317333, doi:10.1007/s11146-007-9053-7. 


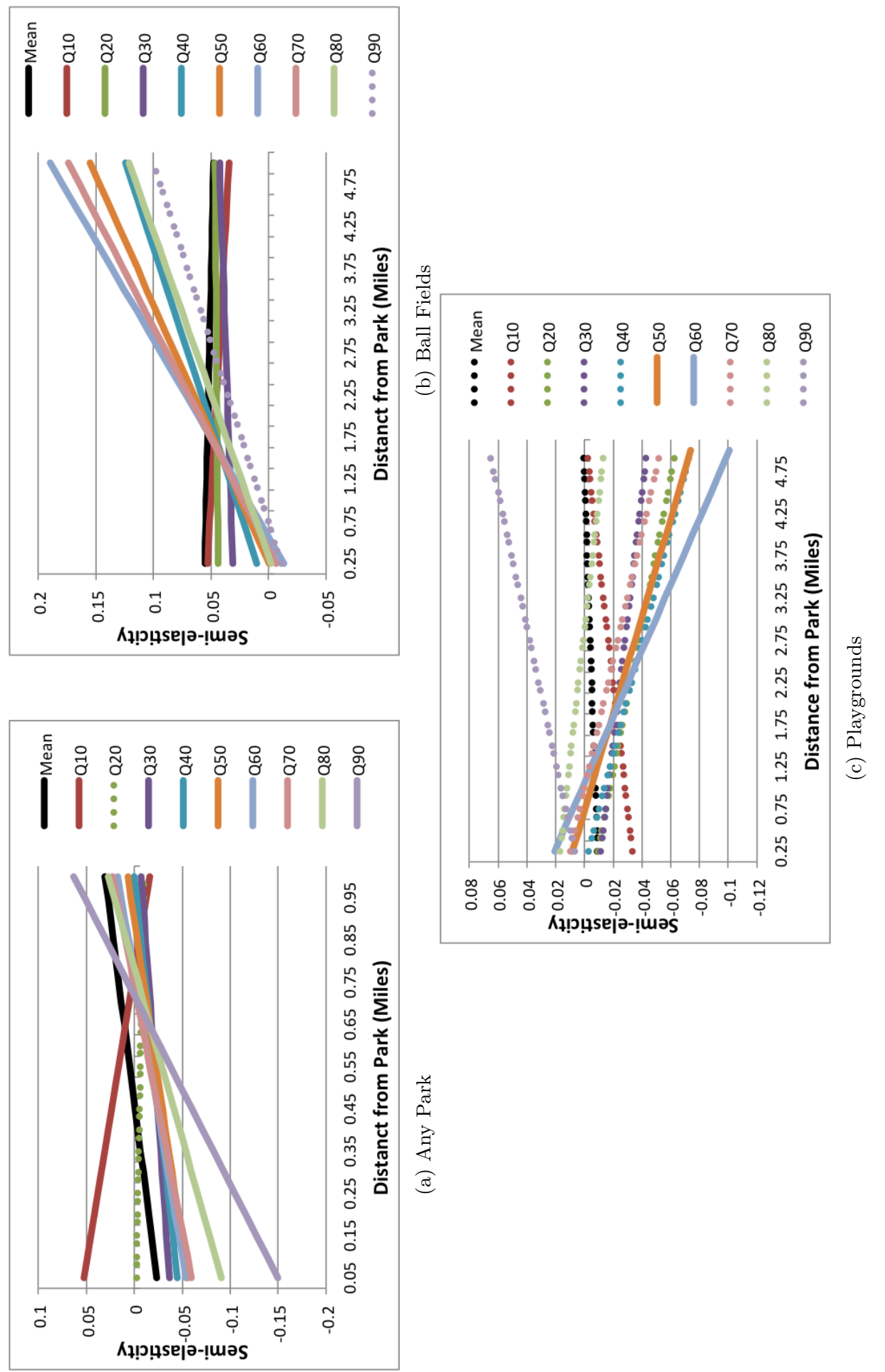

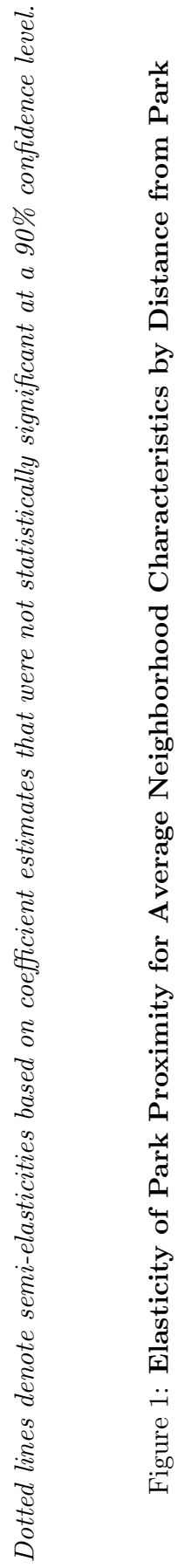



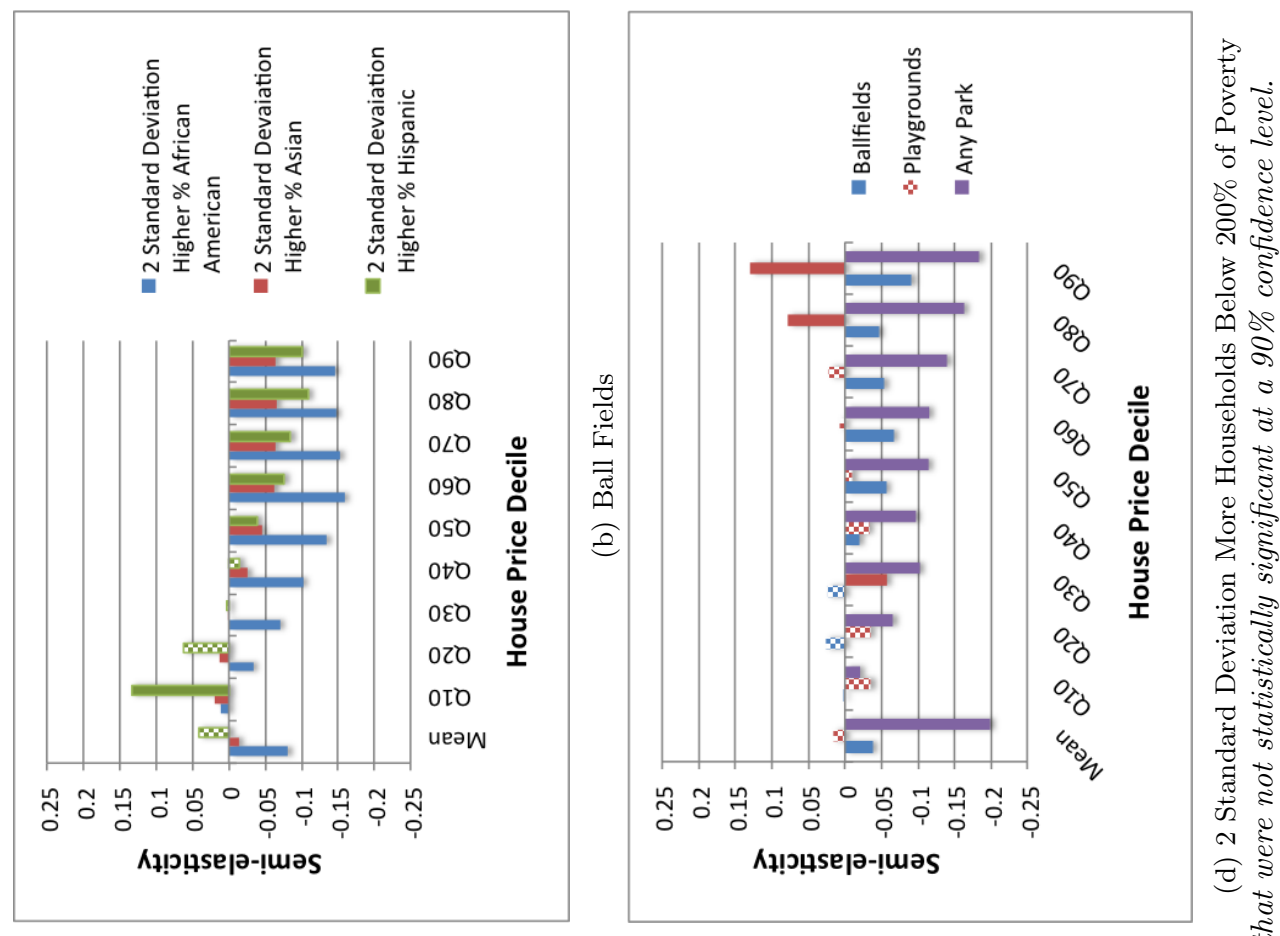

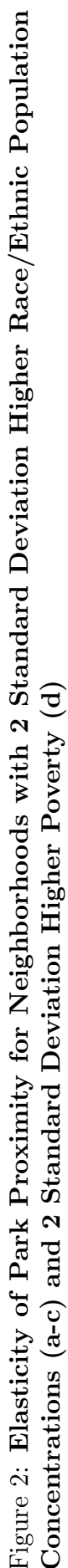
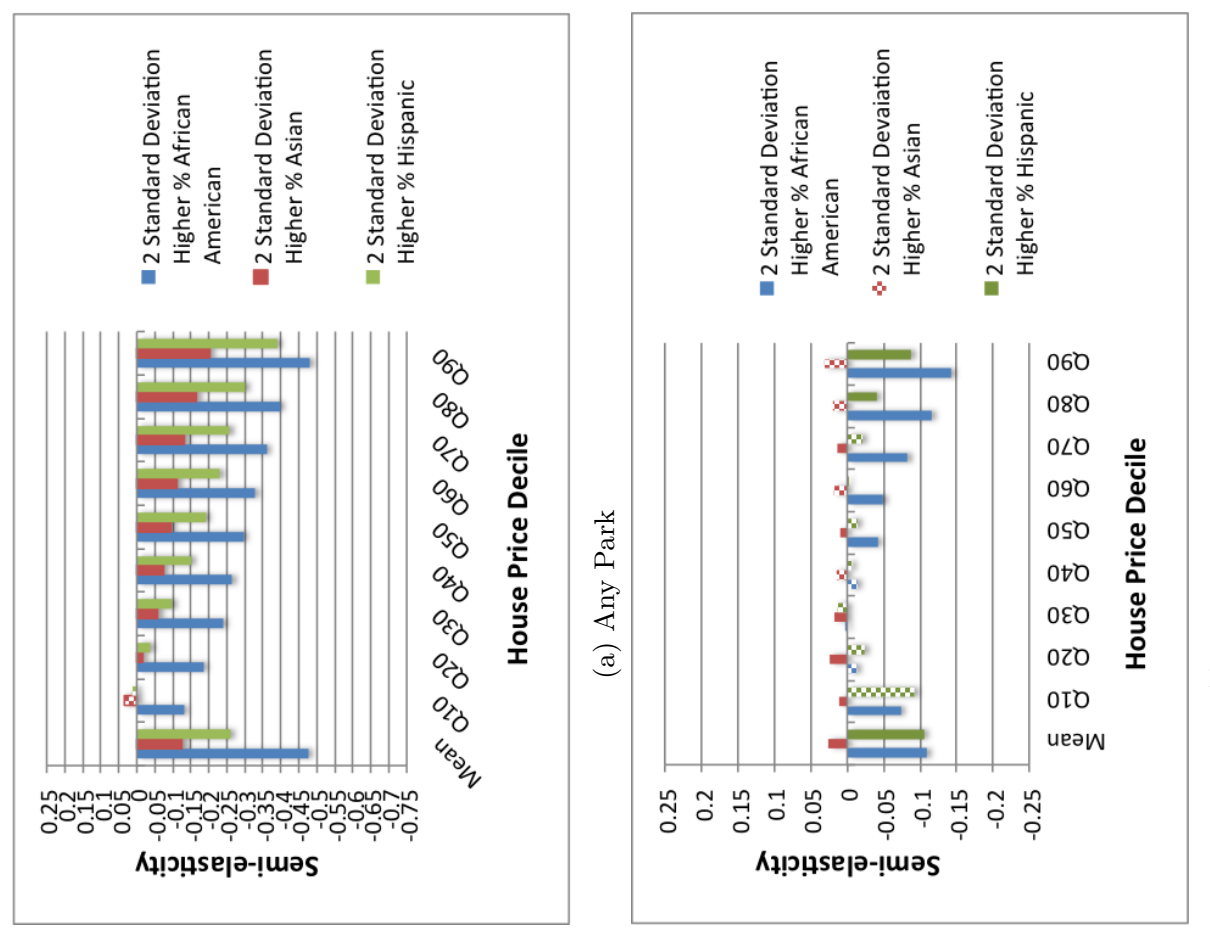


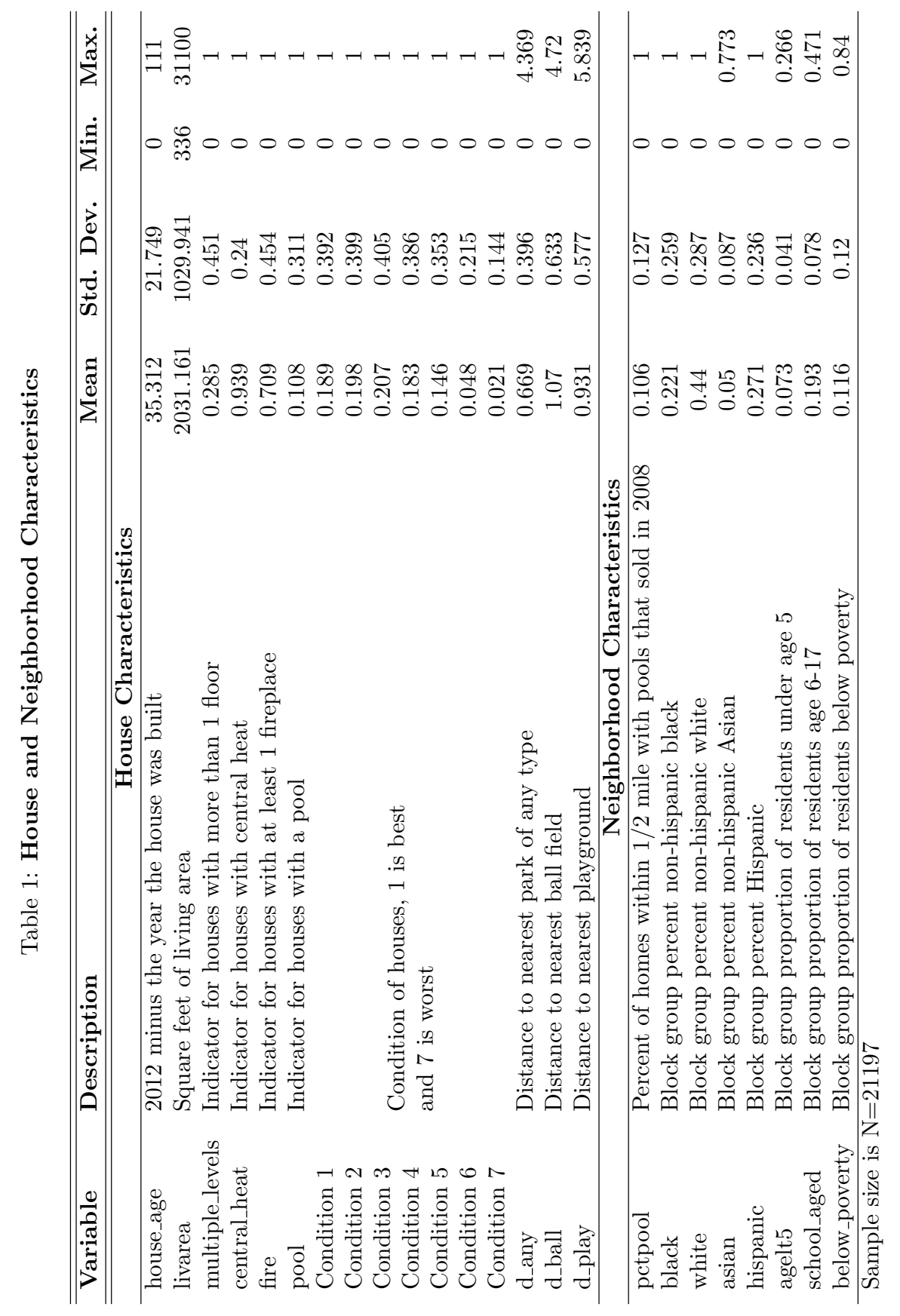


Table 2: Average Proximity for Houses in Neighborhoods with Characteristics that are 2 Standard Deviations above the Mean

\begin{tabular}{|c|c|c|c|c|}
\hline Variable & Mean & Std. Dev. & Min. & Max. \\
\hline \multicolumn{5}{|c|}{ Percent African American Residents, $\mathrm{N}=1621$} \\
\hline d_any & 0.747 & 0.466 & 0.007 & 2.097 \\
\hline d_ball & 1.172 & 0.695 & 0.007 & 2.982 \\
\hline d_play & 1.073 & 0.629 & 0.007 & 3.006 \\
\hline \multicolumn{5}{|c|}{ Percent Asian Residents, $\mathrm{N}=\mathbf{8 8 0}$} \\
\hline d_any & 0.653 & 0.384 & 0 & 1.751 \\
\hline d_ball & 1.139 & 0.63 & 0 & 3.262 \\
\hline d_play & 0.968 & 0.549 & 0 & 2.669 \\
\hline \multicolumn{5}{|c|}{ Percent Hispanic Residents, $N=1021$} \\
\hline d_any & 0.617 & 0.282 & 0.002 & 1.703 \\
\hline d_ball & 0.999 & 0.545 & 0.011 & 2.518 \\
\hline d_play & 0.8 & 0.414 & 0.011 & 2.334 \\
\hline \multicolumn{5}{|c|}{ Proportion of Children less than 5 Years Old, $N=637$} \\
\hline d_any & 0.648 & 0.365 & 0.004 & 1.756 \\
\hline d_ball & 0.981 & 0.512 & 0.053 & 2.98 \\
\hline d_play & 0.98 & 0.577 & 0.004 & 2.971 \\
\hline \multicolumn{5}{|c|}{ Proportion of School Aged Children, $\mathrm{N}=402$} \\
\hline d_any & 0.572 & 0.342 & 0.001 & 1.537 \\
\hline d_ball & 0.971 & 0.473 & 0.034 & 2.299 \\
\hline d_play & 0.79 & 0.472 & 0.03 & 2.619 \\
\hline \multicolumn{5}{|c|}{ Percent of Households Below $200 \%$ of Poverty, $N=780$} \\
\hline d_any & 0.535 & 0.262 & 0.01 & 1.722 \\
\hline d_ball & 0.838 & 0.478 & 0.01 & 2.518 \\
\hline d_play & 0.693 & 0.367 & 0.01 & 2.223 \\
\hline
\end{tabular}


Table 3: Average Park Proximity for Each Decile of Home Prices

\begin{tabular}{|c|c|c|c|c|}
\hline Variable & Mean & Std. Dev. & Min. & Max. \\
\hline \multicolumn{5}{|c|}{ Decile $1[\$ 3510, \$ 54530], \mathrm{N}=2122$} \\
\hline d_any & 0.604 & 0.328 & 0.01 & 2.711 \\
\hline d_ball & 0.862 & 0.503 & 0.012 & 4.515 \\
\hline d_play & 0.856 & 0.562 & 0.012 & 4.542 \\
\hline \multicolumn{5}{|c|}{ Decile $2[\$ 54560, \$ 75570], \mathrm{N}=2119$} \\
\hline d_any & 0.646 & 0.363 & 0.001 & 2.545 \\
\hline d_ball & 0.991 & 0.583 & 0.001 & 3.372 \\
\hline d_play & 0.899 & 0.576 & 0.001 & 4.322 \\
\hline \multicolumn{5}{|c|}{ Decile $3[\$ 75580, \$ 91550], N=2119$} \\
\hline d_any & 0.671 & 0.375 & 0.004 & 2.428 \\
\hline d_ball & 1 & 0.577 & 0.01 & 3.872 \\
\hline d_play & 0.891 & 0.524 & 0.005 & 3.872 \\
\hline \multicolumn{5}{|c|}{ Decile $4[\$ 91560, \$ 107500], N=2120$} \\
\hline d_any & 0.68 & 0.39 & 0 & 2.349 \\
\hline d_ball & 1.028 & 0.61 & 0 & 3.416 \\
\hline d_play & 0.936 & 0.569 & 0 & 4.08 \\
\hline \multicolumn{5}{|c|}{ Decile $5[\$ 107520, \$ 124360], \mathrm{N}=2119$} \\
\hline d_any & 0.695 & 0.422 & 0.001 & 4.369 \\
\hline d_ball & 1.065 & 0.663 & 0.001 & 4.476 \\
\hline d_play & 0.943 & 0.618 & 0.001 & 5.839 \\
\hline \multicolumn{5}{|c|}{ Decile $6[\$ 124380, \$ 146570], \mathrm{N}=2122$} \\
\hline d_any & 0.72 & 0.452 & 0.002 & 4.277 \\
\hline d_ball & 1.15 & 0.699 & 0.006 & 4.385 \\
\hline d_play & 0.999 & 0.636 & 0.006 & 5.747 \\
\hline \multicolumn{5}{|c|}{ Decile $7[\$ 146580, \$ 179910], \mathrm{N}=2118$} \\
\hline d_any & 0.713 & 0.437 & 0.001 & 2.611 \\
\hline d_ball & 1.135 & 0.652 & 0.005 & 3.341 \\
\hline d_play & 0.995 & 0.605 & 0.015 & 4.177 \\
\hline \multicolumn{5}{|c|}{ Decile $8[\$ 179930, \$ 237800], N=2120$} \\
\hline d_any & 0.693 & 0.418 & 0.001 & 2.916 \\
\hline d_ball & 1.104 & 0.61 & 0.007 & 4.72 \\
\hline d_play & 0.944 & 0.576 & 0.003 & 3.806 \\
\hline \multicolumn{5}{|c|}{ Decile $9[\$ 237860, \$ 355720], \mathrm{N}=2120$} \\
\hline d_any & 0.647 & 0.371 & 0 & 2.576 \\
\hline d_ball & 1.17 & 0.638 & 0.002 & 4.453 \\
\hline d_play & 0.940 & 0.552 & 0 & 3.38 \\
\hline \multicolumn{5}{|c|}{ Decile $10[\$ 355780, \$ 13000000], N=2119$} \\
\hline d_any & 0.62 & 0.369 & 0 & 2.509 \\
\hline d_ball & 1.195 & 0.693 & 0.001 & 4.247 \\
\hline d_play & 0.906 & 0.523 & 0.001 & 2.901 \\
\hline
\end{tabular}




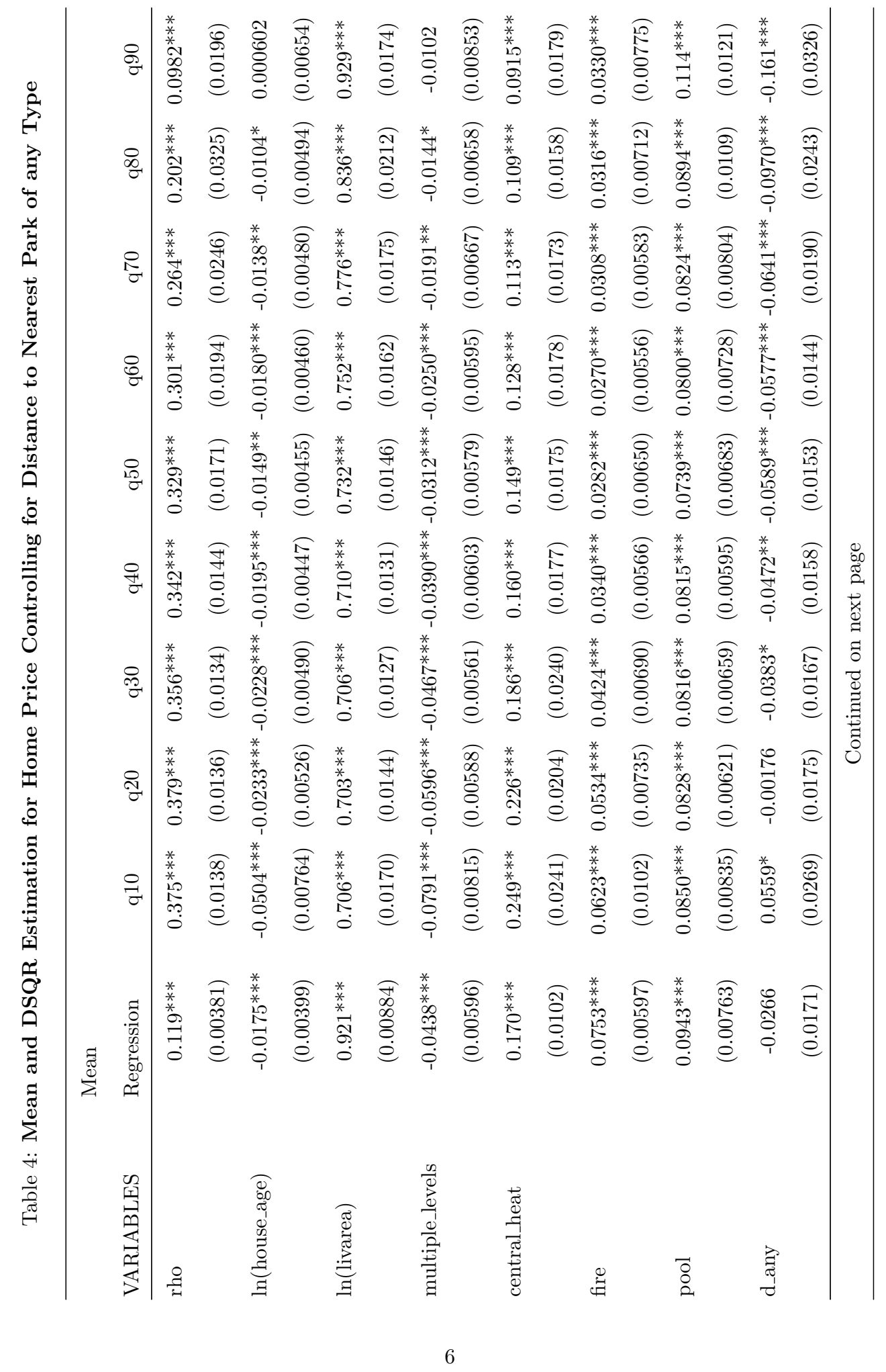




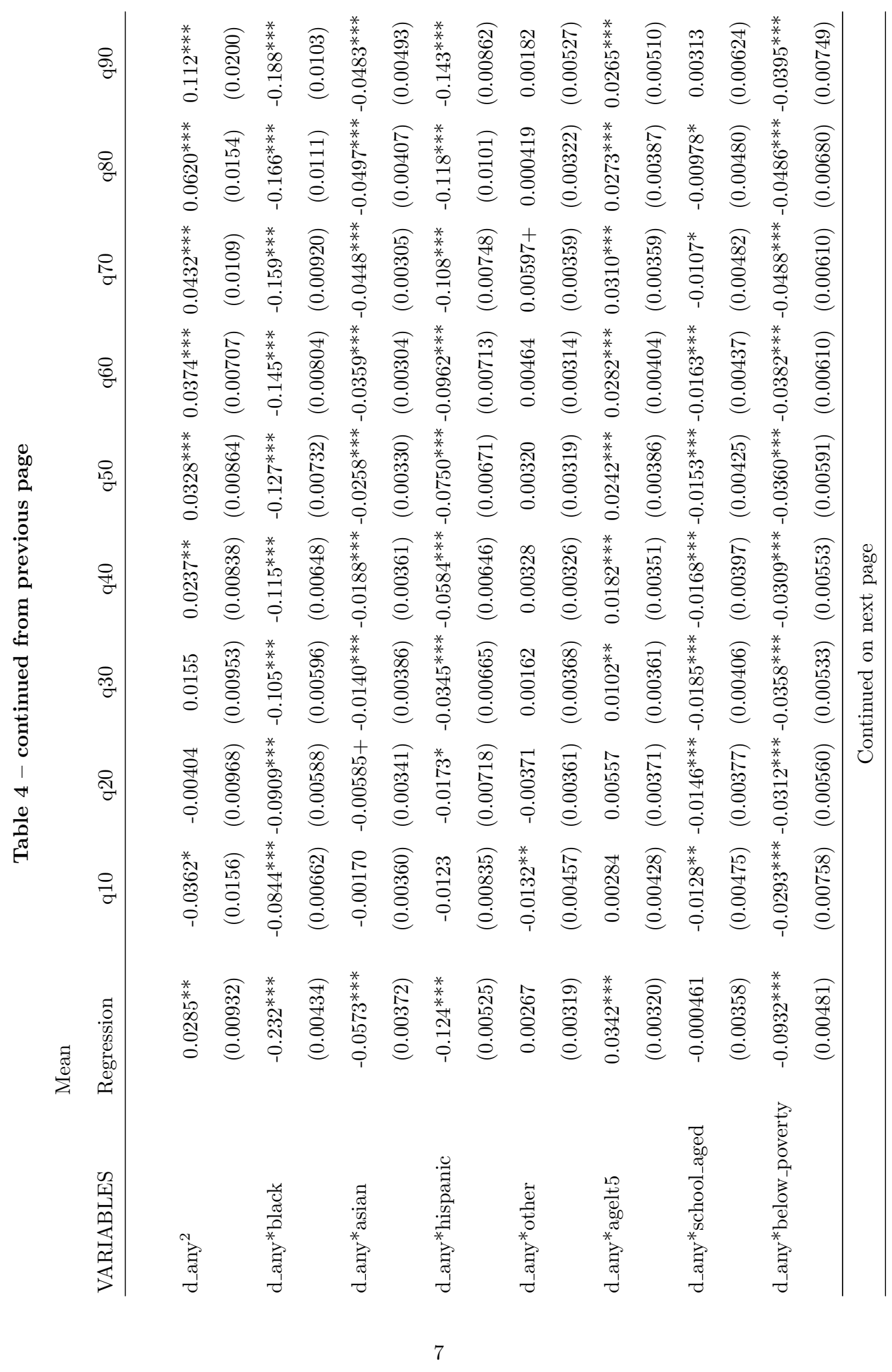




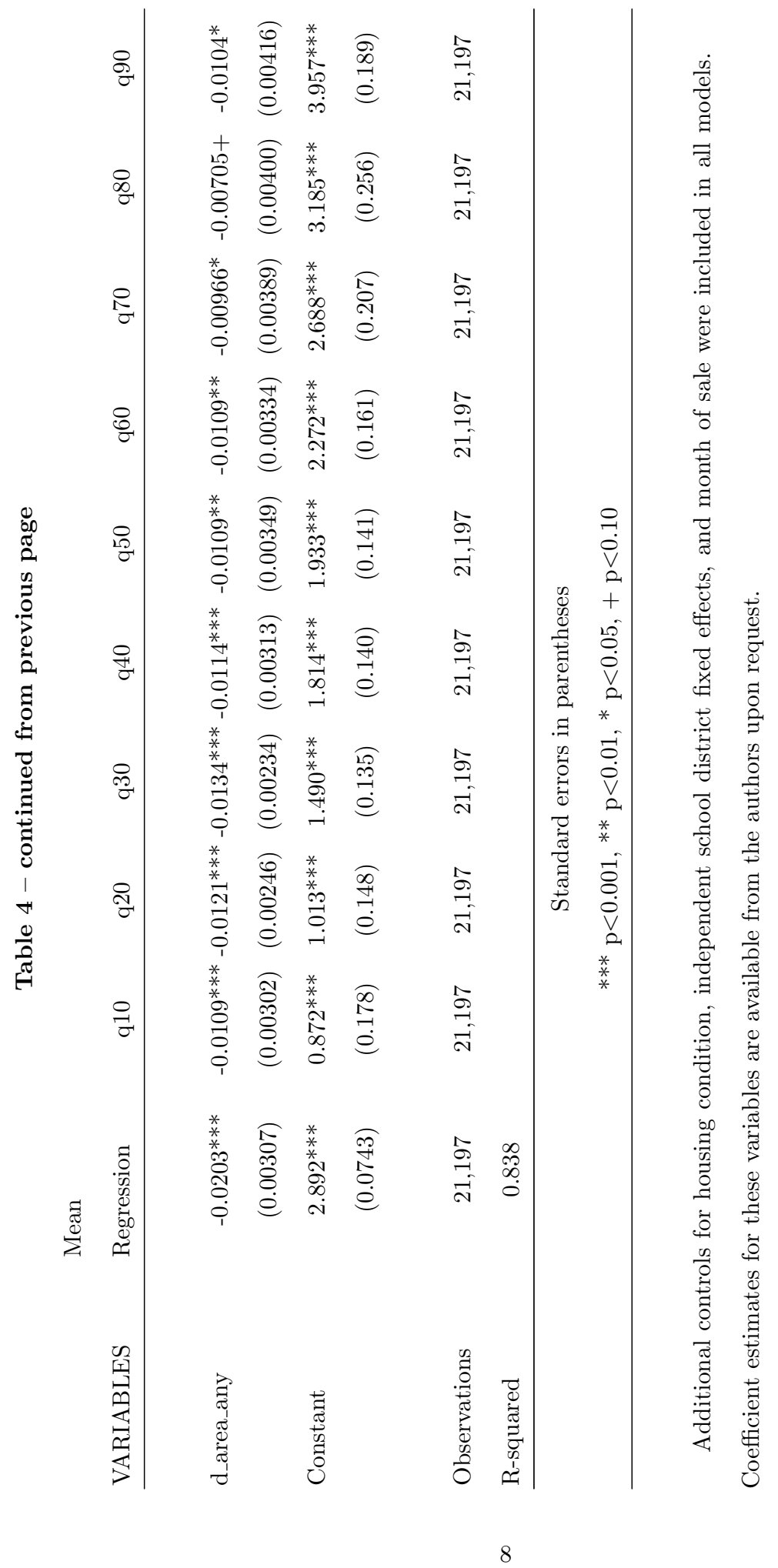




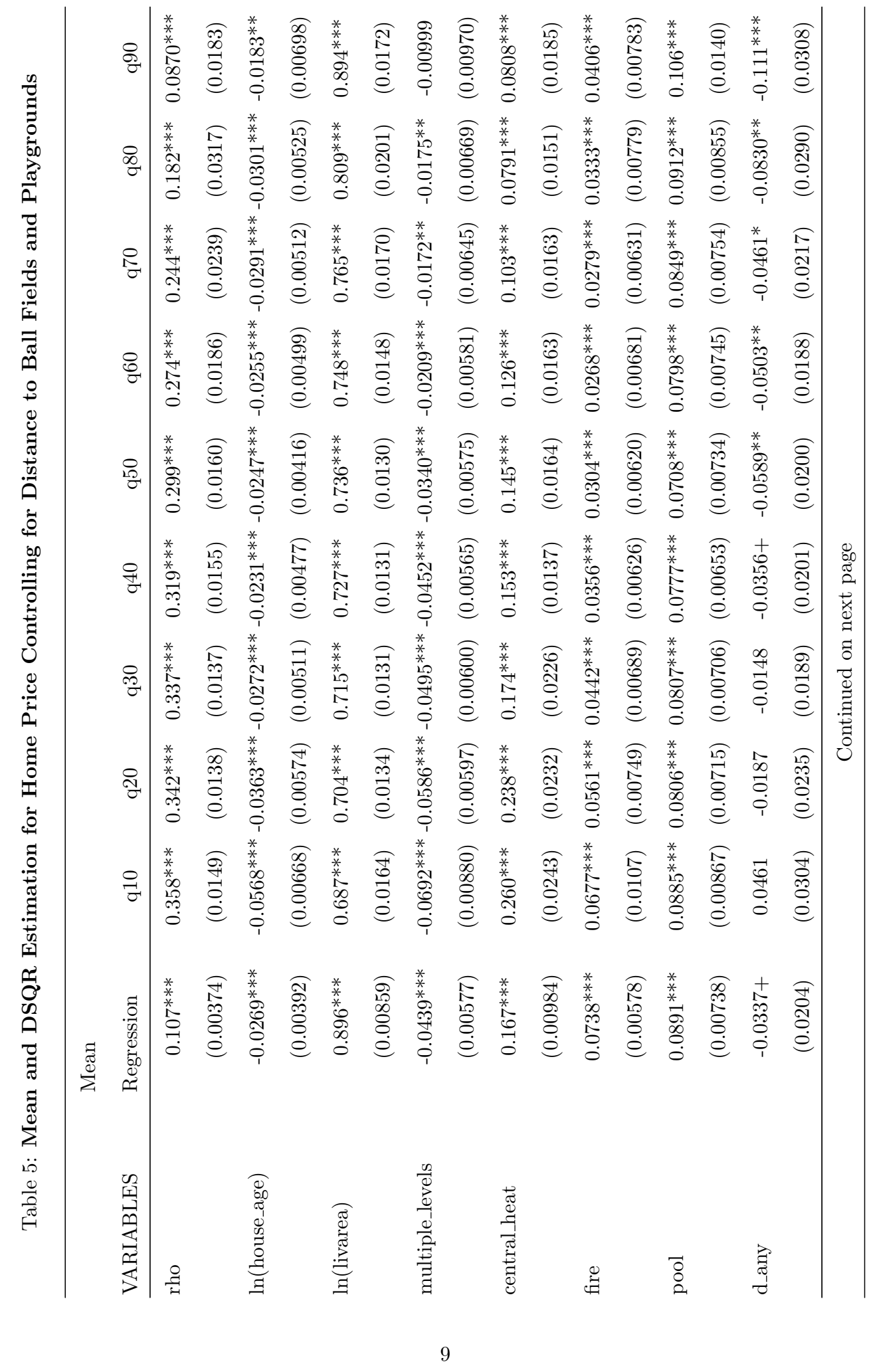




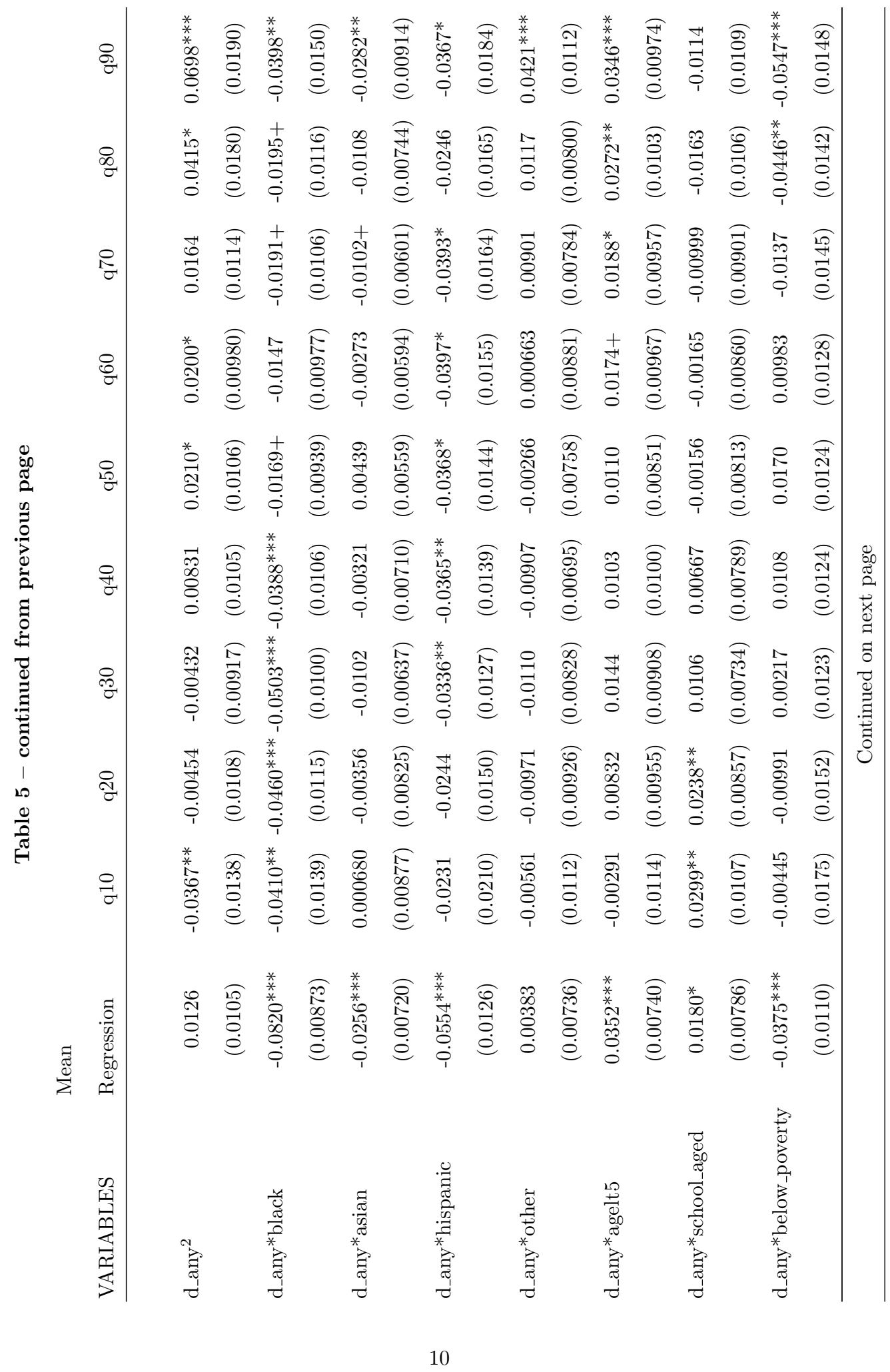




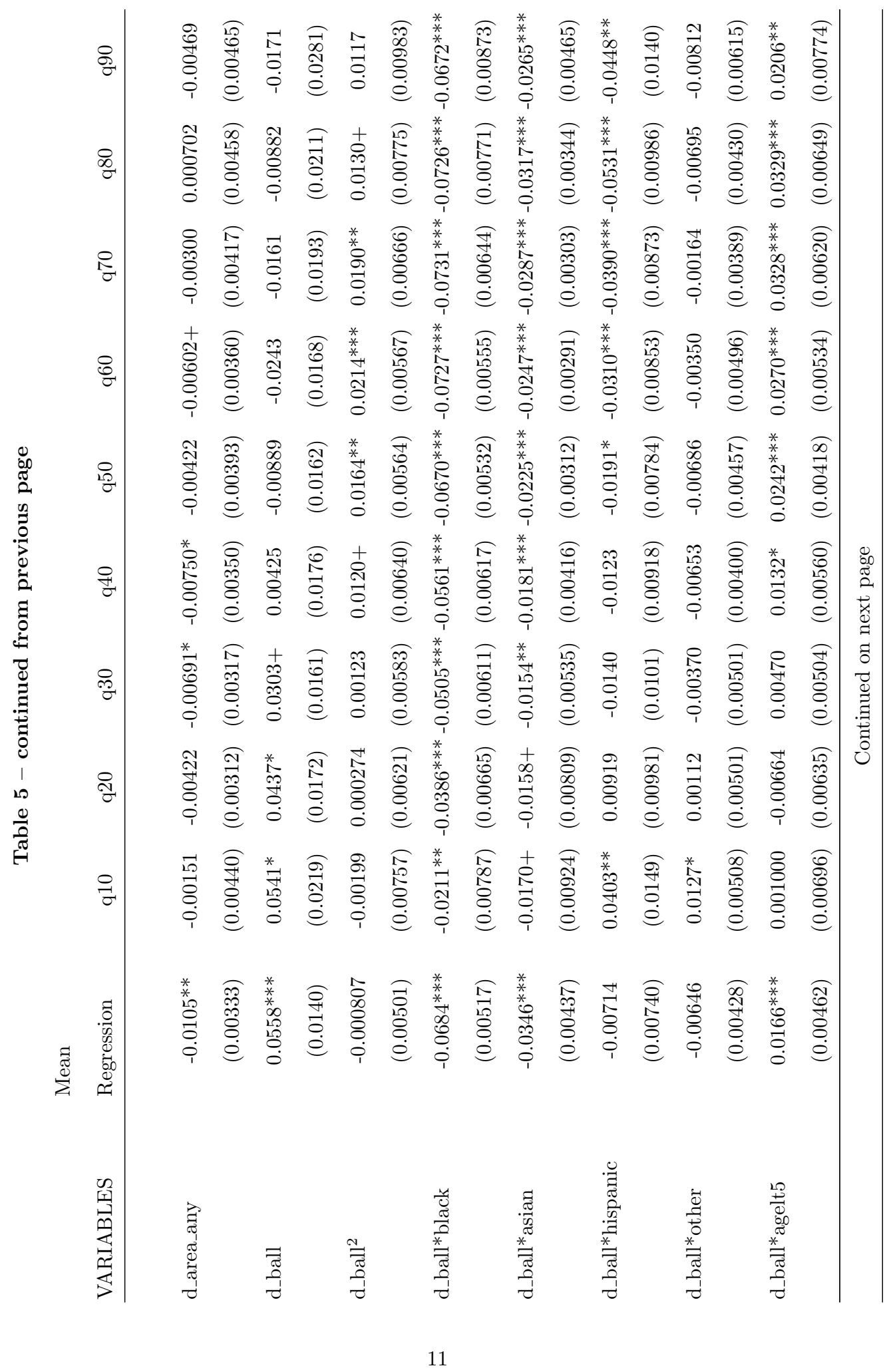




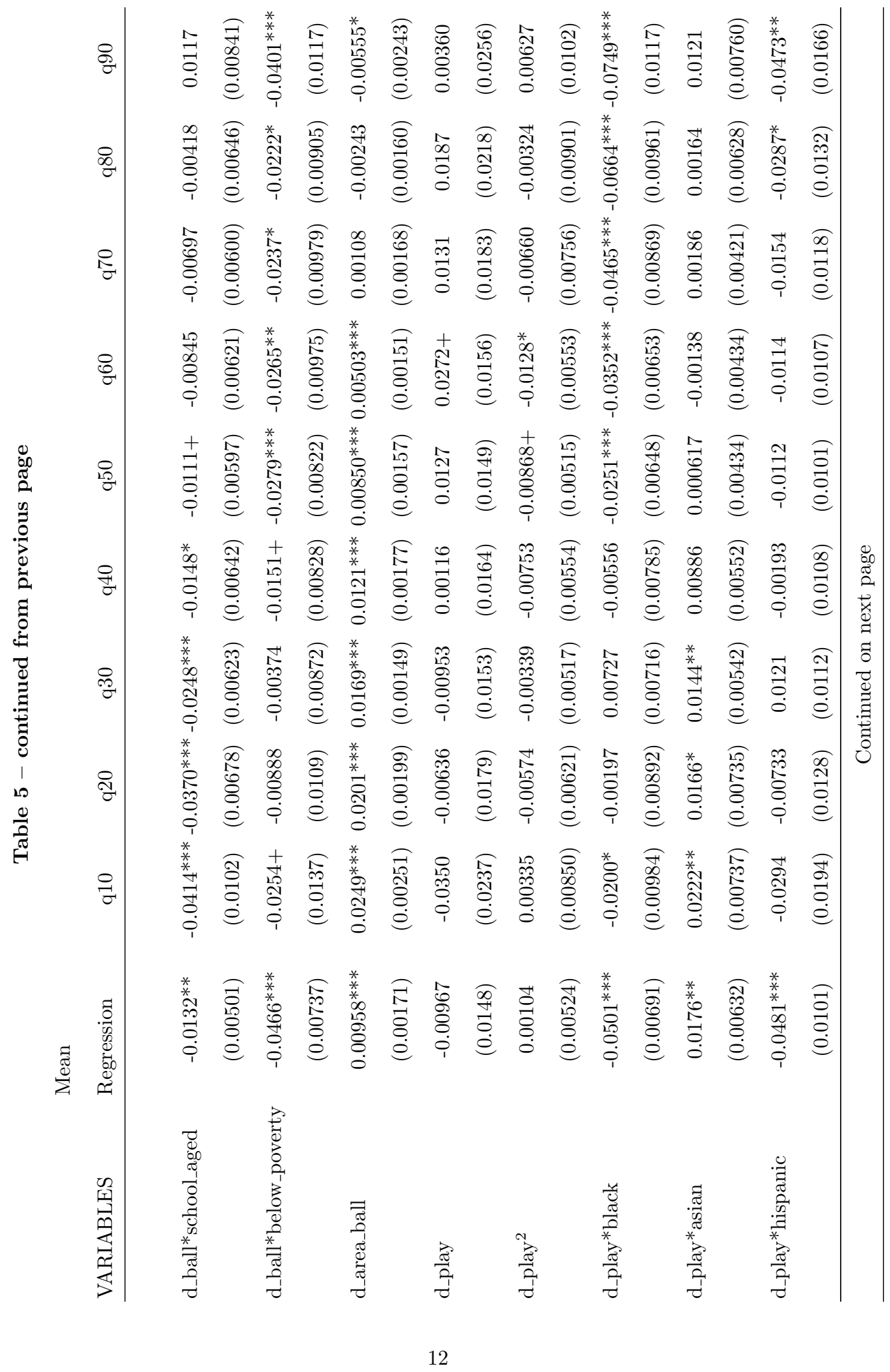




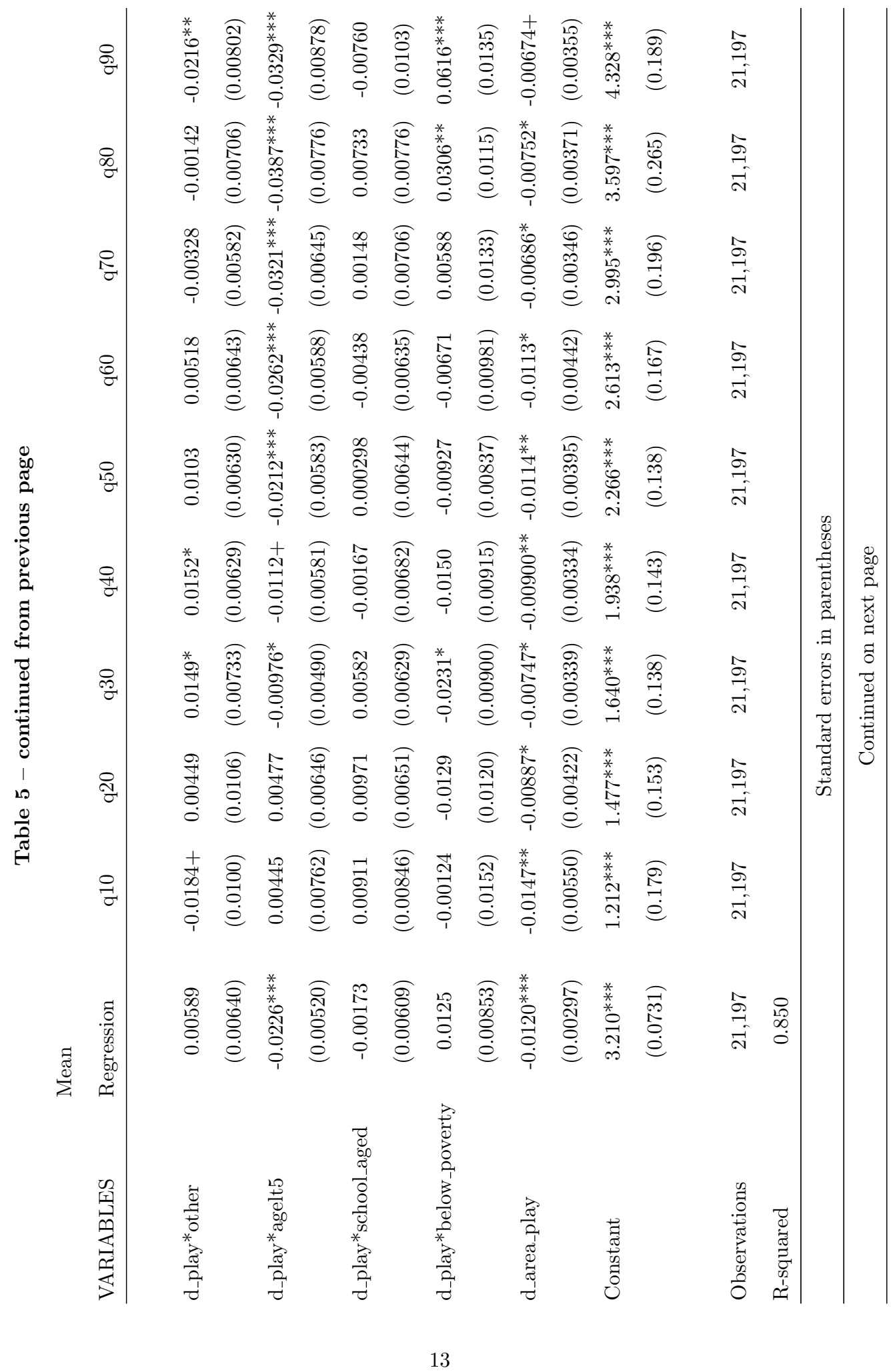




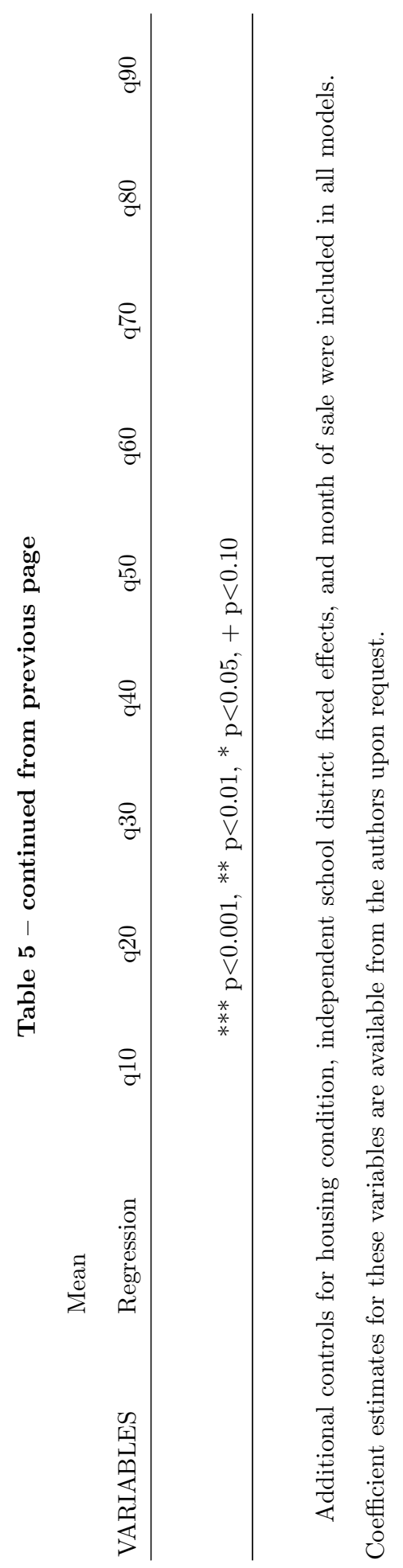

